\title{
MOLECULAR CHARACTERIZATION OF VEROCYTOTOXIGENIC ESCHERICHIA COLI O157:H7 ISOLATES FROM ARGENTINA BY MULTIPLE-LOCI VNTR ANALYSIS (MLVA)
}

\author{
Bustamante, Ana V. ${ }^{1,2}$; Lucchesi, Paula M.A. ${ }^{1,2}$; Parma, Alberto E. ${ }^{1,3}$ \\ Laboratorio Inmunoquímica y Biotecnología, Departamento de Sanidad Animal y Medicina Preventiva, Faculdad Ciêcias \\ Veterinarias, Universidad Nacional del Centro de la Pcia. de Buenos Aires, Tandil, Argentina; ${ }^{2}$ Consejo Nacional de \\ Investigaciones Científicas y Técnicas; ${ }^{3}$ Comisión de Investigaciones Científicas-Gobierno Pcia. Buenos Aires.
}

Submitted: February 11, 2009; Returned to authors for corrections: March 06, 2009; Approved: May 15, 2009.

\begin{abstract}
The aim of this work was to adapt described MLVA protocols to the molecular typing and characterization of VTEC O157:H7 isolates from Argentina. Nine VNTR loci were amplified by PCR showing diversity values from 0.49 to 0.73 . Nine MLVA profiles were observed and the cluster analysis indicated both unrelated and closely related VTEC O157:H7 strains. In spite of the limited number of isolates studied, the panel of VNTR used made it possible to perform a first approach of the high genetic diversity of native strains of O157:H7 by MLVA.
\end{abstract}

Key words: MLVA, VTEC O157:H7, molecular characterization, typing

Verocytotoxigenic Escherichia coli (VTEC) represent an important group of pathogens that can cause severe disease in humans, such as bloody diarrhea (BD) and hemolytic uremic syndrome (HUS) $(6,19)$. In Argentina, HUS has the highest worldwide incidence and is one of the major causes of acute and chronic kidney failure in children under 5 years of age $(12,20)$.

Human infections have been associated with undercooked meat, unpasteurized milk or contamined fruit, vegetables or water $(2,5,19,20)$ and cattle are considered the main reservoir of these strains.

In Argentina, O157:H7 is the serotype most frequently isolated from patients with HUS (50- 60\% of cases), however a higher proportion of other serotypes has also been isolated in comparison with non-Latin American countries $(5,12,21)$.
At present, pulsed-field gel electrophoresis (PFGE) is the current gold-standard method of genetic fingerprinting for O157:H7 isolates (23). In spite of the universal implementation of PFGE as a subtyping method and as a foundation of the PulseNet, this technology suffers from some limitations $(3,6,7,22)$.

The complete sequencing of some bacterial genomes made possible the search for new and highly polymorphic molecular markers, such as VNTRs (Variable Number Tandem Repeats). The analysis of multiple VNTR loci (MLVA) appears as a rapid and specific way to discriminate between different isolates of the same serotype using a simple PCR amplification (11). In clonal organisms such as VTEC O157, PFGE does not always provide the maximum discriminatory capacity. Instead, MLVA markers with high

*Corresponding Author. Mailing address: Paraje Arroyo seco s/n (7000) Tandil, Argentina.; Tel/ Fax: +54 2293 439850.; Email: avbustaman@vet.unicen.edu.ar 
diversities can discriminate between closely related isolates (7). Some laboratories have started using this methodology, but the loci included in the analysis differ among them $(3,7$, 9, 10, 16) and as Urdahl et al. (24) comment, there is a need for more comparative studies reporting MLVA typing of $E$. coli $\mathrm{O} 157$.

The objective of the present work was to adapt described MLVA protocols to the molecular typing and characterization of VTEC O157:H7 isolates from Argentina.

Fourteen VTEC isolates of O157:H7 serotype were selected from the culture collection of the Laboratorio de Inmunoquímica y Biotecnología (UNCPBA, Tandil, Argentina) in order to reflect a variety of epidemiologically related and unrelated strains. Isolates had been obtained from cattle reservoirs (FC O157, FB 3, FB 22, FB 80, FB 81, 166p, 174p, 187p, 643p, 652p, 665p), contaminated food (HT 2-15) and patients with diarrhea (Mat 167/ 6, Gal 26). All isolates had then been characterized for $v t$ and eae genotype and genetic profiling by $\operatorname{RAPD}(1,8,13,14,18$, Dr Padola, unpublished data; Dr Padola and Lucchesi, unpublished data; Dr Sanz, unpublished data). FC O157, HT 2 -15, Mat 167 / 6 and Gal 26 strains have no epidemiological link, while the isolates FB 3, FB 22, FB 80, FB 81 (from feedlot cattle) and 166p, 174p, 187p, 643p, 652p, 665p (from grazing cattle), were isolated from the same farm in different samplings (18). The reference strain EDL933, used as a positive control, was kindly provided by Dr. Jorge Blanco (E. coli Reference Laboratory, University of Santiago de Compostela, Lugo, Spain). Suspensions of bacterial cells were boiled for $10 \mathrm{~min}$ and used directly in the PCR reactions.

Nine VNTR loci were selected from the literature according to their genetic diversity index described by Lindstedt et al. (9) (Vhec2, Vhec4 and Vhec7), Noller et al. (16) (TR2, TR3, TR4 and TR7) and Keys et al. (7) (O157-3 and O157-37). The allelic range to be amplified in PCR multiplex reactions was also taken into account.

Amplification conditions were modified from the original papers $(7,9,16)$ and were as follows: two multiplex PCR assays (multiplex I for Vhec2, Vhec4 and Vhec7 loci, and multiplex II for TR3, TR4 and TR7) with annealing temperatures of $50^{\circ} \mathrm{C}$ and $56^{\circ} \mathrm{C}$, respectively, and three monoplex assays (TR2, O157-3, O157-37) with annealing temperatures of $53^{\circ} \mathrm{C}$ for $\mathrm{TR} 2$ and $65^{\circ} \mathrm{C}$ for $\mathrm{O} 157-3$ and O157-37. PCR products were run in 6\% denaturing polyacrylamide gels and detected by silver staining.

The nine VNTRs were amplified with good efficiency in the 15 isolates analyzed and a total of 39 alleles were observed. Twenty five of the observed alleles (64\%) corresponded to those described by Lindsted et al. (9), Noller et al. (16) and Hyytiä-Trees et al. (3), meanwhile 14 have not been previously described. The nomenclature adopted for the alleles in the present paper is based on the number of units repeated in tandem, in agreement with Hyytiä-Trees et al. (3). In this way, it is easier to compare results among laboratories that can employ different primers for the study of the same VNTRs.

The number of alleles observed per locus ranged between 3 (loci TR3 and O157-37) to 7 (locus O157-3) and the D index ranged between 0.49 (loci O157-37) and 0.73 (loci O157-3) (Table 1). The considerable number of alleles observed per locus highlights the genetic variability of the analyzed isolates. The highest $D$ index values were observed in TR2 and O157-3 loci, and this is consistent with observations reported earlier by Noller et al. (16 and 17), Hyytiä-Trees et al. (3) and Murphy et al. (15).

Vhec4, Vhec7, TR2 and TR3 loci could not be amplified in some isolates, therefore suggesting the presence of null alleles (Table 1). Null alleles were taken into account because represent hidden genetic diversity, as they are caused by either PCR amplification failure due to mutations at the primer annealing region or by the complete deletion of the VNTR region and its flanking sequences (3). In addition, there is experimental evidence that the regions bordering VNTR loci are highly susceptible to mutagenic events (25).

Results detected by gel electrophoresis and silver staining were confirmed and studied in more detail by sequencing representative alleles for each locus. Differences in the size of the alleles were mostly due to the loss or gain of 
repeat units. Alleles that presented partial repeats were rounded up or down to closest complete repeat number, in agreement with Hyytiä-Trees et al. (3).

Short motif VNTRs with repeat units harboring less than six bases are prone to variation in unit number at a given locus (25), and most of the VNTR loci included in this MLVA protocol are short motif repeats with repeat units of six or seven base pairs. However, VNTRs with repeat units longer than 8 base pairs have a greater chance to present point mutations (25) and in accordance with this, we could observe several of this kind of mutations in Vhec 2 alleles, which are 18 base pair-long per unit. We observed insertions, invertions and transvertions (Data not shown).

The MLVA assay displayed 9 distinct profiles among the 15 isolates analyzed. MLVA profiles were defined by the allele string in the order: Vhec2,Vhec4,Vhec7,TR2,TR3,TR4,TR7,O157-3,O157-37. Six isolates corresponded to MLVA profile $9,11,6,12,2,5,9,7,6$ and two to profile $8,11,8,13,2,5,7,12,6$. The other isolates had unique MLVA profiles. The number of MLVA profiles observed was in a similar proportion to that detected by other authors studying a larger number of samples (9).

Table 1. VNTR characterization.

\begin{tabular}{|c|c|c|c|c|c|c|c|c|c|}
\hline $\mathbf{L o c i}^{\mathbf{a}}$ & $\begin{array}{c}\text { Vhec2 } \\
\text { (TR6, } \\
\text { O157-34) }\end{array}$ & $\begin{array}{c}\text { Vhec4 } \\
\text { (TR1, } \\
\text { O157-9) }\end{array}$ & $\begin{array}{c}\text { Vhec7 } \\
\text { (0157- } \\
\text { 36) }\end{array}$ & $\begin{array}{c}\text { TR2 } \\
\text { (Vhec1, } \\
\text { O157-10) }\end{array}$ & $\begin{array}{c}\text { TR3 } \\
\text { (O157- } \\
\text { 17) }\end{array}$ & $\begin{array}{c}\text { TR4 } \\
\text { (O157- } \\
\text { 25) }\end{array}$ & $\begin{array}{c}\text { TR7 } \\
\text { (O157- } \\
\text { 19) }\end{array}$ & $\begin{array}{c}\text { O157-3 } \\
\text { (Vhec3, } \\
\text { TR5) }\end{array}$ & 0157-37 \\
\hline $\mathrm{RU}(\mathrm{bp})^{\mathrm{b}}$ & 18 & 6 & 7 & 6 & 6 & 6 & 6 & 6 & 6 \\
\hline $\mathrm{N}^{\circ}$ of alleles & 4 & 4 & 4 & 5 & 3 & 4 & 5 & 7 & 3 \\
\hline Null alleles & no & yes & yes & yes & yes & no & no & no & no \\
\hline$D^{\mathrm{c}}$ & 0.62 & 0.65 & 0.65 & 0.72 & 0.51 & 0.51 & 0.65 & 0.73 & 0.49 \\
\hline
\end{tabular}

The dendrogram constructed by UPGMA (Figure 1) grouped the isolates in two main clusters (A and B) with subclusters (I, II, III and IV). Cluster A grouped bovine isolates from the same farm and cluster B grouped the rest of the isolates. The patient isolate Gal 26 branched independently from the previously cited groups (subcluster IV), as it presented a very different MLVA profile, differing in more than seven VNTRs from the other isolates. In concordance with the origin of the samples, the differences found among non related isolates were greater than those presented by isolates from the same farm. The isolates from grazing cattle and isolates FB3 and FB80 from feedlot cattle were within subcluster I, which was divided in two branches (Ia and $\mathrm{Ib}$ ) differing by five loci. However, isolates from the same feedlot (FB22 and FB81), branched in another subcluster (II) and differed from subcluster Ib by six loci. The difference within subcluster II was by one incomplete repeat unit in one locus (TR7). These results indicate that they constitute a group of closely related strains, according to the guidelines for MLVA data interpretation suggested by Noller et al. (17).

It is important to take into acount that UPGMA method does not penalize with differential weight different kind of characters, so a point mutation has the same value than either the insertion or deletion of a complete repeat unit and also than a change involving several repeat units. Interpretation of the mutation model of VNTRs is needed in order to determine an appropriate method for performing cluster 
analysis of MLVA data (3).

The panel of VNTR used in this study represents an attractive alternative to characterize VTEC O157:H7. In spite of the limited number of isolates subjected to the present study, this MLVA assay made it possible to perform a first approach of the genetic diversity of native strains of O157:H7.

Argentina has the highest worldwide incidence of HUS, with around 400 cases reported annually. At present, the typing of VTEC isolates by PFGE is performed in a single reference center that receives samples from different locations of our country. It would be interesting to consider the implementation of typing protocols, like the one we used, which can be implemented in many laboratories for molecular epidemiological studies. The amplification efficiency achieved for the VNTRs analyzed, the high diversity found at each locus, and the ability to cluster related VTEC O157:H7 strains, give support to consider this MLVA protocol a useful alternative for the molecular characterization of a large number of VTEC O157:H7 isolates.

\section{ACKNOWLEDGEMENTS}

The authors thank M.R. Ortiz for her technical assistance. This work was supported by grants from the Consejo Nacional de Investigaciones Científicas y Técnicas (CONICET), Comisión de Investigaciones CientíficasGobierno Pcia. Buenos Aires (CIC), FONCYT and SECYTUNICEN. A.V.B. and P.M.A.L. are members of the Research Career of CONICET. A.E.P. is a member of the Research Career of CIC.
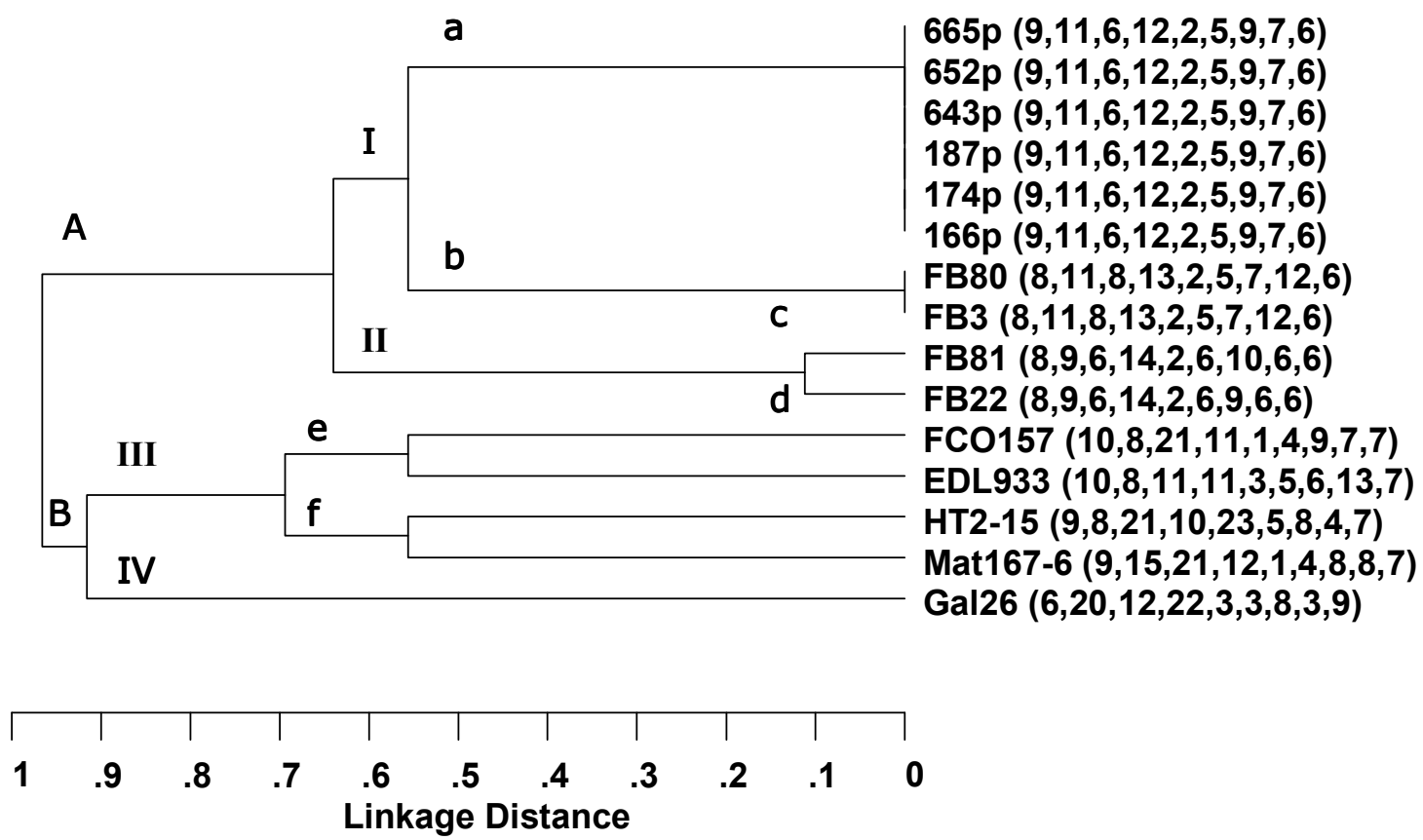

Figure 1. Clustering of 14 E.coli O157:H7 native isolates and EDL933. The dendrogram based on MLVA data was generated using the UPGMA clustering method implemented by START Vs. 1.0.5 software (4). The alleles encoded as 20, 21, 22 and 23 correspond to null alleles. 


\section{REFERENCES}

1. Blanco, M.; Padola, N.L.; Krüger, A.; Sanz, M.; Blanco, J.E.; González, E.A.; Dhabi, G.; Mora, A.; Bernárdez, M.I.; Etcheverría, A.I.; Arroyo, G.H.; Lucchesi, P.M.A.; Parma, A.E.; Blanco, J. (2004). Virulence genes and intimin types of Shiga-toxin-producing Escherichia coli isolated from cattle and beef products in Argentina. Int Microbiol 7(4):269-276.

2. Caprioli, A.; Morabito, S.; Brugere, H.; Oswald, E. (2005). Enterohaemorrhagic Escherichia coli: emerging issues on virulence and modes of transmission. Vet Res 36:289-311.

3. Hyytiä-Trees, E.; Smole, S.C., Field, P.A.; Swaminathan, B.; Ribot E.M. (2006). Second generation Subtyping: A Proposed PulseNet Protocol for Multiple-Locus Variable-Number Tandem Repeat Analysis of Shiga Toxin-Producing Escherichia coli O157 (STEC). Foodborne Pathog. Dis 3 (1): 118-131.

4. Jolley, K.A.; Feil, E.J.; Chan, M.S.; Maiden, M.C. (2001). Sequence type analysis and recombinational tests (START). Bioinformatics 17(12): 1230-1231

5. Karch, H.; Tarr, P.I.; Bielaszewska, M. (2005). Enterohaemorrhagic Escherichia coli in human medicine. Int J Med Microbiol 295 (6):405418.

6. Karmali, M.A. (1989). Infection by verocytotoxin-producing Escherichia coli. Clin Microbiol Rev 2, 15-38.

7. Keys, C.; Kemper, S.; Keim, P. (2005). Highly diverse variable number tandem repeat loci in the E. coli $\mathrm{O} 157: \mathrm{H} 7$ and $055: 7$ genomes for highresolution molecular typing. J Appl Microbiol 98: 928-940.

8. Krüger, A.; Padola, N.L.; Parma, A.E.; Lucchesi, P.M.A. (2006). Intraserotype diversity among Argentinian verocytotoxigenic Escherichia coli detected by random amplified polymorphic DNA analysis. J Med Microbiol 55:545-549.

9. Lindstedt, B.A.; Heir, E.; Gjernes, E.; Vardund T.; Kapperud G. (2003). DNA fingerprinting of Shiga-toxin producing Escherichia coli 0157 based on Multiple-Locus Variable-Number Tandem-Repeats Analysis (MLVA). Ann Clin Microbiol Antimicrob 2:12.

10. Lindstedt, B.A.; Vardund, T., L.; Kapperud, G. (2004). Multiple-locus variable-number tandem-repeats analysis of Escherichia coli $\mathrm{O} 157$ using PCR multiplexing and multicolored capillary electrophoresis. $J$ Microbiol Methods 58:213-222.

11. Lindstedt, B.A. (2005). Multiple- locus variable number tandem repeats analysis for genetic fingerprinting of pathogenic bacteria. Electrophoresis 26: 2567-2582.

12. López, E.L.; Contrini, M.M.; De Rosa, M.F. (1998). Epidemiology of Shiga toxin-producing Escherichia coli in South America. In: Kaper, J. B., O’Brien, A. D. (Eds.), Escherichia coli O157:H7 and other Shiga toxin-producing E. coli strains, ASM Press, Washington D. C., pp. $30-$ 37.
13. Lucchesi, P.M.A.; Krüger, A.; Padola, N.L.; Sanz, M.E.; Parma, A.E. (2003). Diferenciación por la técnica de RAPD de cepas de Escherichia coli verocitotoxigénico. Convención nacional de profesionales de las Ciencias Veterinarias para la producción alimentaria sostenible y el control de alimentos. Congreso veterinario sobre producción, seguridad y calidad alimentaria sostenible y Encuentro nacional de salud pública veterinaria. Villa Giardino, Córdoba, Argentina.

14. Lucchesi, P.M.A.; Krüger, A.; Parma, A.E. (2006). Distribution of saa gene variants in verocytotoxigenic Escherichia coli isolated from cattle and food. Res Microbiol 157:263-266.

15. Murphy, M.; Minihan, D.; Buckley J.F.; O’Mahony, M.; Whyte, P.; Fanning, S. (2008). Multiple-locus variable number of tandem repeat analysis (MLVA) of Irish verocytotoxigenic Escherichia coli O157 from feedlot cattle: uncovering strain dissemination routes. BMC Vet $\operatorname{Res} 4: 2$.

16. Noller, A.C.; McEllistrem, M.C.; Pacheco, A.G.; Boxrud, D.J.; Harrison, L.H. (2003). Multilocus variable-number tandem repeat analysis distinguishes outbreak and sporadic Escherichia coli O157:H7 isolates. J Clin Microbiol 41:5389-5397.

17. Noller, A.C.; McEllistrem, M.C.; Shutt, K.A.; Harrison, L.H. (2006). Locus-Specific Mutational Events in a Multilocus Variable-Number Tandem Repeat Analysis of Escherichia coli O157:H7. J Clin Microbiol 44 (2): 374-377.

18. Padola, N.L.; Sanz, M.E.; Blanco, J.E.; Blanco, M.; Blanco, J.; Etcheverría, A.I.; Arroyo, G.H.; Usera, M.A.; Parma, A.E. (2004). Serotypes and virulence genes of bovine Shigatoxigenic Escherichia coli (STEC) isolated from a feedlot in Argentina. Vet Microbiol 100:39

19. Paton, J.C.; Paton, A.W. (1998). Pathogenesis and Diagnosis of Shiga Toxin-Producing Escherichia coli Infections. Clin Microbiol Rev $11: 450-479$

20. Rivero, M.A.; Padola, N.L.; Etcheverría, A.I.; Parma, A. (2004). Escherichia coli enterohemorrágica y síndrome urémico hemolítico en Argentina. Medicina (Buenos Aires) 64:352-356.

21. Rivas, M.; Balbi, L.; Miliwebsky, E.S.; García, B.; Tous, M.I.; Laerdini, N.A.; Prieto, M.A.; Chillemi, G.M.; de Principi, M.E.T. (1998). Síndrome urémico hemolítico en niños de Mendoza, Argentina. Asociación con la infección por Escherichia coli productor de toxina shiga. Medicina (Buenos Aires) 58: 1-7.

22. Shima, K.; Wu, Y.; Sugimoto, N.; Asakura, M.; Nishimura K.; Yamasaki, S. (2006). Comparison of a PCR- restriction fragment length polymorphism (PCR-RFLP) assay to pulsed- field gel electrophoresis to determine the effect of repeated subculture and prolonged storage on RFLP patterns of Shiga toxin- producing Escherichia coli. J Clin Microbiol 44(11):3963-3968.

23. Swaminatan, B.; Barret, T.J.; Hunter, S.B.; Tauxe, R.V. (2001). PulseNet: the molecular subtyping network for foodborne bacterial disease surveillance, Unite State. Emerg. Infect Dis 7:382-389. 
Bustamante, A.V. et al.

24. Urdahl, A.M.; Strachan, N.J.C.; Wasteson, Y.; MacRae, M.; Ogden, I.D. (2008). Diversity of Escherichia coli $\mathrm{O} 157$ in a longitudinal farm study using multiple-locus variable-number tandem-repeat analysis. $J$ Appl Microbiol 105 (5): 1344-1353
25. van Belkum A.; Scherer, S.; van Alphen, L.; Verbrugh, H. (1998). Short sequence DNA repeats in prokaryotic genomes. Microbiol Mol Biol Rev 62(2):275-293. 